\title{
Experiences of adolescent and young adult cancer survivors during the COVID-19 pandemic
}

\author{
Adam Yan ${ }^{1,2,3} \cdot$ Kaitlyn Howden ${ }^{4}$ Alyson L. Mahar ${ }^{5,6} \cdot$ Ian Scott $^{7} \cdot$ Camille Glidden $^{8}$. Julie Deleemans ${ }^{9}$. \\ Karine Chalifour $^{10}$. Geoff Eaton ${ }^{10}$. Abha Gupta ${ }^{1,11}$. James M. Bolton ${ }^{5,12}$. Sheila N. Garland ${ }^{13} \cdot$ Sapna Oberoi $^{4,14,15}$ (D)
}

Received: 14 November 2021 / Accepted: 20 December 2021 / Published online: 31 January 2022

(c) The Author(s), under exclusive licence to Springer Science+Business Media, LLC, part of Springer Nature 2021

\begin{abstract}
Purpose This study aimed to evaluate the impact of the COVID-19 pandemic on adolescent and young adult (AYA) cancer survivors.

Methods We conducted a cross-sectional survey of AYAs aged 18-49 with cancer in Canada between January and February 2021. Data from survivors, defined as AYAs more than one year off cancer treatment, were analysed. Multiple logistic regression was used to identify factors associated with psychological distress, loneliness and insomnia.

Results The analysis included 384 survivors. Moderate-to-severe psychological distress was reported by 257 (68.9\%) survivors and was associated with an income $\geq \$ 60,000$ (adjusted odds ratio [AOR] 2.15, 95\% CI 1.11-4.17) and the presence of a pre-existing chronic physical health condition (AOR 2.05, 95\% CI 1.18-3.56). Loneliness was reported by 204 (54.0\%) survivors and was associated with being unemployed (AOR 2.26 95\% CI 1.18-4.31), pandemic causing finances to be worse (AOR 1.82, 95\%CI 1.08-3.06) and the presence of a pre-pandemic mental health condition (AOR 1.88, 95\% CI 1.03-3.42). Clinical insomnia was reported by $74(19.5 \%)$ survivors and was associated with employment status as a student (AOR $3.00,95 \%$ CI 1.08-8.29) or unemployed (AOR 3.97, 95\% CI 1.46-10.83), earning $\$ 60,000$ or more in the year 2020 (AOR 4.36, 95\% CI 1.43-13.32), having haematologic cancer (AOR 2.21, 95\% CI 1.05-4.70) and being single (AOR 2.52, 95\% CI 1.08-5.91). Pandemic negatively affected employment, finances, physical activity, cancer care and substance use for $73.9 \%$, $66.5 \%, 32.5 \%, 21.8 \%$ and $19.2 \%$ of survivors, respectively. Worries about finances, contracting COVID-19, cancer treatment increasing the risk of COVID-19 infection, and having poor health outcomes from contracting COVID-19 were reported by $46.0 \%, 45.6 \%, 55.0 \%$ and $47.3 \%$ of survivors, respectively.

Conclusions The COVID-19 pandemic has had a significant impact on AYA cancer survivors, and these individuals report high levels of psychological distress, insomnia and loneliness.

Implications for Cancer Survivors.

Cancer survivors are at risk for worsening mental and physical health outcomes during the COVID-19 pandemic. Targeted interventions and support programs are urgently needed to support the mental health of AYA cancer survivors and optimize their health outcomes.
\end{abstract}

Keywords COVID-19 $\cdot$ Adolescents and young adults $\cdot$ Oncology $\cdot$ Pandemic $\cdot$ Survivorship $\cdot$ Cancer

\section{Introduction}

Changes to healthcare delivery and societal interactions as a result of public health policies implemented during the COVID-19 pandemic have put cancer survivors at increased risk for adverse health outcomes [1-3]. To prevent viral

Sapna Oberoi

soberoi@cancercare.mb.ca

Extended author information available on the last page of the article spread, many healthcare centres are limiting in-person appointments, favouring the increased use of telemedicine for the delivery of health care $[4,5]$. As cancer survivors who have completed treatment require less frequent clinical assessment and investigations and may be the first to be switched to virtual follow-up appointments [6]. These changes may limit access to essential in-person physical and mental health resources for this population [1]. Social distancing may also prevent cancer survivors from accessing 
indispensable support systems crucial for coping with the many challenges experienced in the survivorship period [2].

Adolescents and young adults (AYAs) diagnosed with cancer between 15 to 39 years of age often have complex medical, developmental and psychosocial needs. AYAs are more likely to face additional challenges in the survivorship period than their older counterparts [7, 8]. AYA cancer survivors often deal with a myriad of issues ranging from impaired physical and mental health, difficulties in continuing education and finding employment, challenges in finding and maintaining intimate and peer relationships, concerns about body image and fertility and financial hardships [7-9]. The societal and healthcare system shifts caused by the COVID-19 pandemic may worsen the already sub-optimal health and well-being of this population [7, 8, 10-16]. During the early phase of the pandemic, a survey of 177 AYAs with cancer demonstrated that one-fifth of participants completing cancer treatment more than six months ago were experiencing high levels of psychological distress [17]. Another qualitative study of 13 AYAs (18-29 years) with cancer conducted during the pandemic in Denmark found themes related to needing more supportive services, loneliness, challenges in connecting to the community and disruption of development [18].

However, a focused study examining the effect of COVID-19 on various aspects of the lives of AYA cancer survivors is lacking. Recognizing the impact of the ongoing pandemic on this population could provide crucial information that will help bridge the health gaps experienced by AYAs during this pandemic. Therefore, among AYAs who have survived cancer in Canada, we sought to determine the impact of the COVID-19 pandemic on their psychological distress, loneliness, insomnia, physical activity and finances, and to identify sociodemographic-, cancer- and health-related factors associated with psychological distress, loneliness and insomnia.

\section{Methods}

The data for this study were obtained from the impact of the COVID-19 pandemic on AYAs with cancer (ICOVIDAYA) study, a cross-sectional survey of AYAs living in Canada who were either undergoing active cancer therapy or had completed their treatment [19]. Participants were recruited via the social media platforms of the various national AYA cancer support groups across Canada, such as the Young Adult Cancer Canada (YACC) [20] and cancer clinics in Manitoba, to complete a 49-item self-administered anonymous online questionnaire between January and February 2021. The participants provided online informed consent prior to the completion of the survey. The questions relevant to this analysis are listed in Supplemental Methods Sect 1.
Content experts developed the questionnaire using an established survey development methodology [21]. Patients were eligible for the study if they were diagnosed with cancer between 15 to 39 years of age and were currently 18 years of age or older. This paper represents the subset analysis of the ICOVIDAYA survey focusing solely on AYA cancer survivors, aged $18-49$, who were at least one or more years post-treatment. The Research Ethics Board approved the study at the University of Manitoba (HS: 24501).

\section{Survey measures}

We collected sociodemographic information including age (18-25 vs. 26-39. vs. 40-50), gender (man vs. woman), ethnicity (white vs. non-white), Canadian province or territory of residence (British Columbia vs. Prairies vs. Central Canada vs. Atlantic Canada vs. Territories), living environment (urban vs. rural/remote), relationship status (single vs. in a relationship), employment status (employed vs. student vs. unemployed vs. caregiver/homemaker, disability/unemployment benefits vs. other), personal income in the year 2020 in $\mathrm{CAD}(<\$ 40,000$ vs. $\$ 40-60,000$ vs. $\geq \$ 60,000)$, and the number of days of physical activity and exercise per week ( 0 vs. $1-2$ vs. $2-4$ vs. $5-7$ days per week). In addition, we collected information on self-reported pre-pandemic mental health conditions (yes vs. no), and chronic health conditions (yes vs. no) and cancer therapy, including cancer type (haematologic malignancy vs. non-haematologic malignancy) and time off cancer therapy (1-2 years, $2-5$ years, $5-10$ years and $>10$ years). We also collected information related to the impact of COVID-19 on cancer survivors' employment, substance use, physical activity and exercise, the impact of the COVID-19 pandemic on cancer care and finances (a full description of these variables is available in Supplemental Methods Sect. 2). We used self-report validated scales to assess psychological distress, loneliness and insomnia.

\section{Psychological distress}

Psychological distress was determined using the Kessler Psychological Distress Scale (K-10). The K-10 consists of ten questions about emotional states within the last one month. Possible responses consist of "none of the time", "a little of the time", "some of the time", "most of the time", and "all of the time" and are graded as 1-5, respectively. The total K-10 score was calculated by summing the scores from each of the ten questions. Individuals with a total score $\geq 25$ were classified as having high (moderate to severe) psychological distress [22, 23]. 


\section{Loneliness}

The 3-item UCLA Loneliness Score was used to assess selfreported loneliness among survivors over the four weeks preceding the survey. This validated score consists of three questions that assess how often participants feel they lack companionship, feel left out and feel isolated from others. Participants can answer "hardly ever", "some of the time", or "often" for each of the three questions, and those answered are scored as 1, 2, or 3, respectively. A final score is derived from the sum of the three question scores. Individuals with a cumulative score $\leq 5$ are considered not lonely, and individuals with a cumulative score $\geq 6$ are considered lonely $[24,25]$.

\section{Insomnia symptoms}

We used the Insomnia Severity Index (ISI), a validated selfreport scale to assess the nature and severity of insomnia symptoms; this consists of seven questions and has been validated to assess insomnia in individuals with cancer [26, 27]. Participants were asked to rate their difficulty falling asleep, difficulty staying asleep, and problems waking up too early within the last two weeks as "none", "mild", "moderate", "severe" or "very severe," and the answers to these three questions were scored as 0-4, respectively. Survivors were then asked four questions related to satisfaction/dissatisfaction with sleep, noticeability of sleep problems, worry/ distress about people's problems and interference of sleep problems with daily life. These questions were also scored from 0 to 4 . The scores of all seven questions were combined to yield a final ISI score. Participants with scores $\geq 15$ were classified as having moderate-to-severe insomnia [26, 28].

\section{Statistical analysis}

Demographic and clinical variables related to the impact of COVID-19 pandemic were summarized using descriptive statistics. Factors associated with high psychological distress, loneliness and insomnia were investigated using logistic regression. Simple logistic regression with odds ratios and $95 \%$ confidence limits were used to estimate the independent association between high psychologic distress (yes vs. no), loneliness (yes vs. no) and moderate-tosevere insomnia (yes vs. no) and pre-determined variables such as age, sex, ethnicity, geographic location, employment status, personal income, cancer type, presence of self-reported pre-pandemic mental health condition, preexisting chronic physical health condition, relationship status, the impact of the pandemic on employment, finances, substance use, cancer care and physical activity. Multivariable logistic regression was then performed with factors with a p-value $<0.1$ on univariable analysis to determine association with psychologic distress, loneliness and insomnia while adjusting for the influence of other variables. Statistical significance was defined as p-value less than 0.05, and two-sided tests were used. SPSS version 28.0 was used to perform the analysis [29].

\section{Results}

\section{Demographic data}

Of the 1063 individuals who completed the initial survey, 384 were at least one year off cancer treatment and were eligible for this analysis. The reasons for exclusion were: on cancer treatment or within one year of finishing treatment $(n=656)$, did not specify the stage of treatment $(n=15)$, age $<18(n=2)$, and age $>50$ years $(n=6)$. The demographic and clinical data for the cohort are displayed in Table 1. The median age of participants was 30 years. Most patients had recently completed therapy, with 262 (68.2\%) having completed therapy within the past 2 years, $110(28.6 \%)$ having completed therapy within the past 2-5 years and only $12(3.1 \%)$ having completed therapy within the past $5-10$ years. Men $(N=218)$ constituted $57.2 \%$ of the study population. Most participants were white $(N=357,93.0 \%)$, and two-thirds of the participants lived in an urban location $(N=256,67.0 \%)$. The number of survivors engaged in physical activity of $30 \mathrm{~min} /$ day for 0 days, 1-2 days, 2-4 days and 5-7 days per week was 9 (2.4\%), $81(21.3 \%), 190(49.9 \%)$ and 101 (26.5\%), respectively. Seventy-seven (20.4\%) participants reported a pre-pandemic mental health condition, and $165(43.0 \%)$ of participants reported a pre-existing chronic physical health condition. The majority of participants had non-haematologic malignancies $(N=301,78.4 \%)$.

\section{Impact of COVID-19 pandemic on employment, finances, cancer care, physical activity, substance use, and COVID-19 pandemic-related worries}

Figure 1 shows the impact of COVID-19 pandemic on employment, finances, cancer care, physical activity and substance use. The number of AYA cancer survivors who reported that pandemic affected their employment was 284 (73.9\%): $85(22.1 \%)$ quit, $105(27.3 \%)$ were laid off and $94(24.5 \%)$ were laid off but were working again at the time of the survey. Nearly two-thirds $(66.5 \%)$ of survivors conveyed that their finances got worse during the pandemic. A negative impact of the pandemic on cancer care was reported by $83(21.8 \%)$ of survivors. More physical activity, the same level of physical activity and less physical activity compared to pre-pandemic were reported by 47 (12.3\%), $203(53.1 \%)$ and $124(32.5 \%)$ of survivors, respectively, while $8(2.1 \%)$ indicated that they do not 
Table 1 Demographics of the study population $(n=384)$

\begin{tabular}{|c|c|c|}
\hline Study variable & $\mathrm{n}$ & $\%$ \\
\hline \multicolumn{3}{|l|}{ Age (years) } \\
\hline $18-25$ & 78 & $20.3 \%$ \\
\hline $26-39$ & 281 & $73.2 \%$ \\
\hline $40-50$ & 25 & $6.5 \%$ \\
\hline \multicolumn{3}{|l|}{ Gender* } \\
\hline Man & 218 & $57.2 \%$ \\
\hline Woman & 163 & $42.8 \%$ \\
\hline \multicolumn{3}{|l|}{ Ethnicity } \\
\hline White & 357 & $93.0 \%$ \\
\hline Non-white & 27 & $7.0 \%$ \\
\hline \multicolumn{3}{|l|}{ Province or Territory } \\
\hline Central Canada ${ }^{\mathrm{a}}$ & 78 & $20.3 \%$ \\
\hline Prairies $^{\mathrm{b}}$ & 124 & $32.3 \%$ \\
\hline British Columbia & 43 & $11.2 \%$ \\
\hline Atlantic Canada ${ }^{\mathrm{c}}$ & 99 & $25.8 \%$ \\
\hline Canadian Territories $^{\mathrm{d}}$ & 40 & $10.4 \%$ \\
\hline \multicolumn{3}{|l|}{ Living Environment** } \\
\hline Urban & 256 & $67.0 \%$ \\
\hline Rural or Remote & 126 & $33.0 \%$ \\
\hline \multicolumn{3}{|l|}{ Relationship Status** } \\
\hline Single & 152 & $39.8 \%$ \\
\hline In a relationship & 230 & $60.2 \%$ \\
\hline \multicolumn{3}{|l|}{ Employment Status ${ }^{\dagger e}$} \\
\hline Employed (part or full time) & 249 & $65.5 \%$ \\
\hline Student & 47 & $12.4 \%$ \\
\hline Unemployed & 59 & $15.5 \%$ \\
\hline Caregiver/homemaker & 13 & $3.4 \%$ \\
\hline Disability or unemployment benefits & 9 & $2.4 \%$ \\
\hline Other (Eg.Leave of absence) & 3 & $0.8 \%$ \\
\hline \multicolumn{3}{|l|}{ Personal income in $2020(\mathrm{CAD} \$)^{\ddagger}$} \\
\hline$<\$ 40,000$ & 90 & $24.4 \%$ \\
\hline$\$ 40,000-<\$ 60,000$ & 144 & $39.0 \%$ \\
\hline$\geq \$ 60,000$ & 135 & $36.6 \%$ \\
\hline \multicolumn{3}{|l|}{ Cancer type } \\
\hline Haematologic malignancy & 83 & $21.6 \%$ \\
\hline Non-haematologic malignancy & 301 & $78.4 \%$ \\
\hline \multicolumn{3}{|l|}{ Time off of cancer therapy } \\
\hline $1-2$ years & 262 & $68.2 \%$ \\
\hline $2-5$ years & 110 & $28.6 \%$ \\
\hline $5-10$ years & 12 & $3.1 \%$ \\
\hline$>10$ years & 0 & $0.0 \%$ \\
\hline \multicolumn{3}{|l|}{ Pre-pandemic mental health condition ${ }^{\text {f§ }}$} \\
\hline Yes & 77 & $20.4 \%$ \\
\hline No & 300 & $79.6 \%$ \\
\hline \multicolumn{3}{|l|}{ Pre-existing chronic physical health illness ${ }^{\mathrm{g}}$} \\
\hline Yes & 165 & $43.0 \%$ \\
\hline No & 219 & $57.0 \%$ \\
\hline \multicolumn{3}{|c|}{ Number of days/week of physical activity or exercise* } \\
\hline 0 days & 9 & $2.4 \%$ \\
\hline $1-2$ days & 81 & $21.3 \%$ \\
\hline
\end{tabular}

Table 1 (continued)

\begin{tabular}{cll}
\hline Study variable & $\mathrm{n}$ & $\%$ \\
\hline 2-4 days & 190 & $49.9 \%$ \\
5-7 days & 101 & $26.5 \%$ \\
\hline
\end{tabular}

a Ontario, Quebec; ${ }^{\mathrm{b}}$ Alberta, Saskatchewan, Manitoba; ${ }^{\mathrm{c}}$ Newfoundland and Labrador, Nova Scotia, New Brunswick, Prince Edward Island; ${ }^{\mathrm{d} Y u k o n, ~ N o r t h w e s t ~ T e r r i t o r i e s, ~ N u n a v u t ; ~}{ }^{\mathrm{e}}$ Multiple option choices could be selected; ${ }^{\mathrm{f}} \mathrm{Eg}$. Personality disorder, ADHD; ${ }^{\mathrm{g}} \mathrm{Eg}$. Autoimmune diseases, seizure disorder

${ }^{*} \mathrm{~N}=381, \quad * *=\mathrm{N}=382,{ }^{\dagger} \mathrm{N}=380,{ }^{\dagger} \mathrm{N}=369,{ }^{\S} \mathrm{N}=377, \quad{ }^{\dagger} \mathrm{N}=378$,

${ }^{\dagger} \mathrm{N}=373,{ }^{\S \S} \mathrm{N}=379,{ }^{* \dagger} \mathrm{N}=368, *{ }^{\S} \mathrm{N}=372,{ }^{\dagger \S} \mathrm{N}=354$

exercise. Increased substance use during pandemic was reported by $73(19.2 \%)$ of survivors, while $103(27.0 \%)$ reported a reduction in substance intake when compared to pre-pandemic years. Supplemental Fig. 1 shows the worries of the survivors related to the COVID-19 pandemic. Worries about contracting COVID-19 infection, cancer treatment increasing the risk of acquiring COVID19 infection, having poor health outcomes from contracting COVID-19 infection, and finances were reported by $45.6 \%, 55.0 \%, 47.3 \%$ and $46.0 \%$ of survivors, respectively.

\section{Psychological distress}

High psychological distress was reported by $68.9 \%$ $(N=257)$ of survivors. On univariable analysis, increasing age, male gender, rural living environment, higher income and presence of a pre-existing chronic physical health condition were associated with a greater odds of experiencing high psychological distress $(p<0.05)$. On multivariable analysis, the factors independently associated with high psychological distress were an income greater than or equal to $\$ 60,000$ in the year 2020 (adjusted odds ratio [AOR] 2.15, 95\% CI 1.11-4.17, $p=0.02$ ) and the presence of a chronic physical health condition (AOR 2.05, 95\% CI $1.18-3.56, p=0.01)$ (Table 2).

\section{Loneliness}

Loneliness was reported by 204 (54.0\%) of survivors. On univariable analysis, unemployment, COVID-19 pandemic negatively affecting finances and presence of a pre-pandemic mental health condition were associated with a greater odds of experiencing loneliness $(p<0.0 .05)$. On multivariable analysis, the factors independently associated with loneliness were an employment status of unemployed (AOR 2.26 95\% CI 1.18-4.31, $p=0.013$ ), pandemic causing finances to be worse (AOR 1.82, 95\% CI 1.08-3.06, $p=0.024$ ) and the 
Fig. 1 Self-reported impact of COVID-19 pandemic on employment, finances, cancer care, substance use, and physical activity

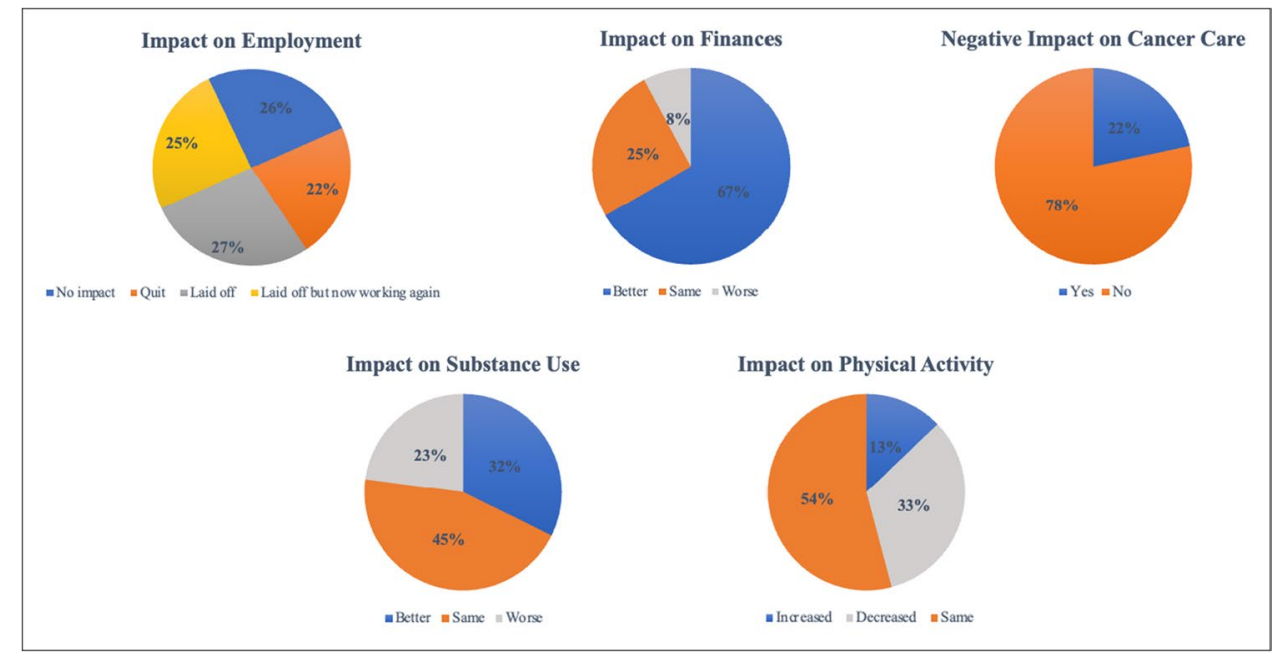

presence of a pre-pandemic mental health condition (AOR $1.88,95 \%$ CI 1.03-3.42, $p=0.038$ ) (Table 3).

\section{Insomnia Symptoms}

Moderate-to-severe insomnia symptoms were reported by $74(19.5 \%)$ survivors. On univariable analysis, employment status of unemployed or student, having a diagnosis of a haematologic malignancy, longer time off cancer therapy, having a pre-pandemic mental health condition, being single, COVID-19 pandemic having a negative impact on cancer care and having increased substance use during pandemic were associated with increased odds of experiencing moderate-to-severe insomnia, while reduced substance use was associated with decreased odds of experiencing moderateto-severe insomnia among AYA cancer survivors $(p<0.05)$. On multivariable analysis, the factors independently associated with moderate-to-severe insomnia symptoms were having an employment status as a student (AOR 3.00, 95\% CI 1.08-8.29, $p=0.035$ ) or unemployed (AOR 3.97, 95\% CI 1.46-10.83, $p=0.007)$, earning $\$ 60,000$ or more in the year 2020 (AOR 4.36, 95\% CI 1.43-13.32, $p=0.010$ ), having haematologic cancer (AOR 2.21, 95\% CI 1.05-4.70, $p=0.039$ ), and being single (AOR 2.52, 95\% CI 1.08-5.91, $p=0.033$ ) (Table 4).

\section{Discussion}

This study is the first to explore the experiences of the AYA cancer survivors during the COVID-19 pandemic in Canada. In this sample of 384 AYA survivors who were at least one-year post-completion of cancer therapy, we found that COVID-19 has impacted AYA cancer survivors in various ways. Specifically, we identified high levels of psychological distress (68.9\%), insomnia (19.5\%) and loneliness (54.0\%).
Given that cancer survivors are at an increased risk of many physical and mental health conditions, it is crucial to address modifiable risk factors for these conditions [28]. Substance use has been identified as one of the ways some individuals have attempted to cope with stress and emotions related to the loss of social connection and employment during the pandemic [30]. Prior studies have identified that childhood and AYA cancer survivors engage in risk-taking behaviours comparable to or higher than their peers [31, 32]. In our study, although $27.0 \%$ reported improvement in substance use during the pandemic, $19.2 \%$ conveyed that their substance use worsened. A similar pattern in substance use has been observed in the general Canadian population [33]. As substance use can further increase the risk of physical and psychological morbidities among AYA cancer survivors, efforts for screening and reducing substance use are crucial for this population, especially during a pandemic. At the same time, recognizing the factors that lead to a reduction in substance use during the pandemic might assist in shaping future strategies for preventing substance misuse. The decline in the physical activity reported by more than half of the participants is concerning, given the growing body of literature on the vital role of exercise in mitigating the long-term physical, psychological and cognitive sequelae of cancer and its treatment [34]. To prevent the long-term consequences of a sedentary lifestyle, developing novel and creative ways or programs to engage survivors in various physical activities and prevent the persistence of sedentary behaviours acquired during the pandemic is paramount.

During the pandemic, AYA cancer survivors had a significant decline in their finances and employment. Prior to the COVID-19 pandemic, adult and childhood cancer survivors were at an elevated risk for financial hardships and were less likely to be employed [35-37]. Half (49.4\%) of AYA cancer survivors in our survey reported quitting their job or being laid off, and $66.5 \%$ reported that the pandemic 
Table 2 Psychological distress among survivors of AYA cancers during the COVID-19 pandemic

\begin{tabular}{|c|c|c|c|c|c|c|}
\hline \multirow[b]{2}{*}{ Variable } & \multicolumn{3}{|c|}{ Univariable analysis } & \multicolumn{3}{|c|}{ Multivariable analysis $(n=359)$} \\
\hline & Odds Ratio & $95 \% \mathrm{CI}$ & P-Value & $\begin{array}{l}\text { Adjusted } \\
\text { Odds Ratio }\end{array}$ & $95 \% \mathrm{CI}$ & P-Value \\
\hline Age (continuous) & 0.95 & $0.92-0.99$ & 0.015 & 0.96 & $0.92-1.004$ & 0.078 \\
\hline \multicolumn{7}{|l|}{ Gender } \\
\hline $\begin{array}{l}\text { - Female } \\
\text { - Male (ref) }\end{array}$ & 0.62 & $0.40-0.97$ & 0.034 & 0.82 & $0.50-1.35$ & 0.43 \\
\hline \multicolumn{7}{|l|}{ Ethnicity } \\
\hline $\begin{array}{l}\text { - Not white } \\
\text { - White (ref) }\end{array}$ & 2.70 & $0.91-7.98$ & 0.073 & 0.54 & $0.17-1.74$ & 0.30 \\
\hline \multicolumn{7}{|l|}{ Living environment } \\
\hline $\begin{array}{l}\text { - Rural/remote } \\
\text { - Urban (ref) }\end{array}$ & 2.73 & $1.61-4.62$ & $<0.001$ & 1.53 & $0.85-2.79$ & 0.16 \\
\hline \multicolumn{7}{|l|}{ Employment status } \\
\hline $\begin{array}{l}\text { - Unemployed } \\
\text { - Student } \\
\text { - Employed (ref) }\end{array}$ & $\begin{array}{l}2.30 \\
1.60\end{array}$ & $\begin{array}{l}0.96-5.51 \\
0.88-2.90\end{array}$ & 0.14 & & & \\
\hline $\begin{array}{l}\text { Impact of COVID-19 pandemic on employ- } \\
\text { ment } \\
\text { - Impacted } \\
\text { - No impact (ref) }\end{array}$ & 1.25 & $0.71-2.20$ & 0.44 & & & \\
\hline \multicolumn{7}{|l|}{ Personal income in the year 2020} \\
\hline - $\$ 60,000$ or more & 1.47 & $0.85-2.55$ & 0.001 & 2.15 & $1.11-4.17$ & 0.024 \\
\hline $\begin{array}{l}\text { - } \$ 40,000 \text { to less than } \$ 60,000 \\
\text { - Less than } \$ 40,000 \text { (ref) }\end{array}$ & 3.04 & $1.66-5.70$ & & 1.01 & $0.55-1.86$ & 0.97 \\
\hline \multicolumn{7}{|l|}{ Effect of COVID-19 pandemic on finances } \\
\hline $\begin{array}{l}\text { - Worse } \\
\text { - Better } \\
\text { - Same (ref) }\end{array}$ & $\begin{array}{l}0.75 \\
1.12\end{array}$ & $\begin{array}{l}0.44-1.26 \\
0.43-2.95\end{array}$ & 0.39 & & & \\
\hline \multicolumn{7}{|l|}{ Cancer type } \\
\hline $\begin{array}{l}\text { - Haematologic } \\
\text { - Non-haematologic (ref) }\end{array}$ & 1.18 & $0.68-2.02$ & 0.56 & & & \\
\hline \multicolumn{7}{|l|}{ Time off cancer treatment } \\
\hline $\begin{array}{l}-5-10 \text { years } \\
-2-5 \text { years } \\
-1-2 \text { years }(\text { ref })\end{array}$ & $\begin{array}{l}0.52 \\
0.99\end{array}$ & $\begin{array}{l}0.15-1.77 \\
0.61-1.64\end{array}$ & 0.57 & & & \\
\hline \multicolumn{7}{|l|}{ Pre-pandemic mental health condition } \\
\hline $\begin{array}{l}\text { - Yes } \\
\text { - No (ref) }\end{array}$ & 1.36 & $0.76-2.41$ & 0.29 & & & \\
\hline \multicolumn{7}{|l|}{ Pre-existing chronic physical health condition } \\
\hline $\begin{array}{l}\text { - Yes } \\
\text { - No (ref) }\end{array}$ & 3.09 & $1.90-5.02$ & $<0.001$ & 2.05 & $1.18-3.56$ & 0.011 \\
\hline \multicolumn{7}{|l|}{ Relationships status } \\
\hline $\begin{array}{l}\text { - Single } \\
\text { - In relationship (ref) }\end{array}$ & 1.02 & $0.65-1.60$ & 0.92 & & & \\
\hline \multicolumn{7}{|l|}{ Substance use during the pandemic } \\
\hline $\begin{array}{l}\text { - Better } \\
\text { - Worse } \\
\text { - Same (ref) }\end{array}$ & $\begin{array}{l}0.63 \\
1.18\end{array}$ & $\begin{array}{l}0.35-1.12 \\
0.58-2.40\end{array}$ & 0.151 & & & \\
\hline \multicolumn{7}{|l|}{ Negative impact of pandemic on cancer care } \\
\hline - Yes & 0.88 & $0.52-1.48$ & 0.62 & & & \\
\hline
\end{tabular}


Table 2 (continued)

\begin{tabular}{|c|c|c|c|c|c|c|}
\hline \multirow[b]{2}{*}{ Variable } & \multicolumn{3}{|c|}{ Univariable analysis } & \multicolumn{3}{|c|}{ Multivariable analysis $(n=359)$} \\
\hline & Odds Ratio & $95 \% \mathrm{CI}$ & P-Value & $\begin{array}{l}\text { Adjusted } \\
\text { Odds Ratio }\end{array}$ & $95 \% \mathrm{CI}$ & P-Value \\
\hline \multicolumn{7}{|l|}{ - No (ref) } \\
\hline \multicolumn{7}{|c|}{$\begin{array}{l}\text { Impact of COVID-19 pandemic on physical } \\
\text { activity/exercise }\end{array}$} \\
\hline - More active & 0.69 & $0.44-1.73$ & 0.70 & & & \\
\hline - Less active & 0.41 & $0.50-1.33$ & & & & \\
\hline - Same level of activity (ref) & & & & & & \\
\hline
\end{tabular}

negatively affected their finances [38]. The finances of youth have been disproportionately affected during the pandemic, and their re-employment rates have been lower than their older counterparts; this gap may be further exaggerated for AYA cancer survivors, who already face challenges and stigma when seeking employment [39]. Programs specifically designed and targeted to cancer survivors must be created through the joint efforts of cancer organizations, nonprofits and local governments to support survivors overcome their unique barriers to workforce re-entry such as restricted mobility, cognitive impairment, chronic pain, fatigue, need for reduced work hours or special accommodations. Programs targeted to the general population should also be promoted to cancer survivors to support these individuals' financial health and equal employment opportunities as we continue to navigate this pandemic.

The changes in the social fabric of Canadian society as a consequence of COVID-19 precautionary measures have had a significant impact on the mental health of Canadians, and the same holds for cancer survivors. In our study, $68.9 \%$ of survivors reported high psychological distress, which is considerably greater than pre-pandemic reports of psychological distress among AYA cancer survivors (21-29.5\%) $[10,40]$. Pre-pandemic studies also suggest that AYA cancer survivors report significantly higher psychological distress than cancer-free peers [41]. This association holds during the pandemic, with only $17-24 \%$ of Canadian teenagers without a history of cancer reporting symptoms of psychological distress [42]. In our analysis, AYA survivors with a pre-existing physical health issue reported higher levels of psychological distress. This is potentially because a preexisting physical health issue, and being a cancer survivor are independent contributors to psychological distress [43, 44]. This finding also aligns with a recently conducted systematic review reporting higher levels of psychological distress among people with pre-existing chronic health conditions in the general population during this pandemic [45]. We also identified a personal income of $\$ 60,000$ or more in the year 2020 as a risk factor for psychological distress. This finding needs further exploration since it can be confounded by other elements not accounted for in this analysis, such as the Canada Emergency Response Benefit provided by the Canadian government during the pandemic to some individuals, education status, child care responsibilities, homeschooling during the pandemic, work environment and the household income [46].

In addition, more than half (54\%) of AYA cancer survivors met the criteria for loneliness. Compared to a cohort of young adults in Canada without a history of cancer surveyed in November 2020, the prevalence of loneliness in our study was considerably greater (54\% vs. $29 \%$ ) [47]. Compared to two other studies reporting the prevalence of loneliness during the pandemic to be $21-40 \%$ among patients with cancer of varying ages, AYAs with cancer were more likely to report loneliness $[17,48]$. A pre-pandemic study of AYAs with cancer identified these individuals to be more lonely than peers without a history of cancer [49]. AYA cancer survivors with a pre-existing mental health condition were more likely to identify as lonely in our study, which may result from poor coping skills, their pre-existing diagnosis increasing their vulnerability to social isolation and the financial consequences of the pandemic. In addition, unemployed individuals were also more likely to report being lonely, a finding comparable to studies of individuals without a cancer diagnosis [50]. Participants whose finances became worse during the pandemic were also more likely to report loneliness. Individuals whose finances have deteriorated may not engage in standard coping mechanisms, have food and shelter insecurity, and increased interpersonal conflict at home regarding finances due to their declining income, causing a survivor to feel lonelier [51, 52]. As loneliness has been shown to predict suicidal ideation and can have a negative impact on long-term physical and mental health, the high prevalence of loneliness among AYA cancer survivors is of significant concern and needs attention during this pandemic $[53,54]$.

Nearly $20 \%$ of AYA cancer survivors reported moderateto-severe insomnia symptoms. A pre-pandemic report found that insomnia occurred in $30 \%$ of cancer survivors; however, that study used a different insomnia questionnaire and was 
Table 3 Loneliness among survivors of AYA cancers during the COVID-19 pandemic

\begin{tabular}{|c|c|c|c|c|c|c|c|}
\hline & \multicolumn{3}{|c|}{ Univariable analysis } & \multirow[b]{2}{*}{ Adjusted odds ratio } & \multicolumn{3}{|c|}{ Multivariable analysis $(\mathrm{n}=332)$} \\
\hline & Odds ratio & $95 \%$ CI & P-Value & & & $95 \% \mathrm{CI}$ & P-Value \\
\hline Age (continuous) & 1.02 & $0.98-1.05$ & 0.36 & & & & \\
\hline \multicolumn{8}{|l|}{ Gender } \\
\hline $\begin{array}{l}\text { - Female } \\
\text { - Male (ref) }\end{array}$ & 1.15 & $0.76-1.74$ & 0.50 & & & & \\
\hline \multicolumn{8}{|l|}{ Ethnicity } \\
\hline $\begin{array}{l}\text { - Not white } \\
\text { - White (ref) }\end{array}$ & 1.26 & $0.57-2.80$ & 0.57 & & & & \\
\hline \multicolumn{8}{|l|}{$\begin{array}{l}\text { Living environ- } \\
\text { ment }\end{array}$} \\
\hline $\begin{array}{l}\text { - Rural/remote } \\
\text { - Urban (ref) }\end{array}$ & 0.80 & $0.52-1.23$ & 0.31 & & & & \\
\hline \multicolumn{8}{|l|}{$\begin{array}{l}\text { Employment } \\
\text { status }\end{array}$} \\
\hline - Unemployed & 2.26 & $1.23-4.16$ & 0.027 & 2.26 & & $1.18-4.31$ & 0.013 \\
\hline $\begin{array}{l}\text { - Student } \\
\text { - Employed } \\
\text { (ref) }\end{array}$ & 0.95 & $0.51-1.78$ & & 0.92 & & $0.48-1.77$ & 0.81 \\
\hline $\begin{array}{l}\text { Impact of } \\
\text { COVID-19 } \\
\text { pandemic on } \\
\text { employment } \\
\text { - Impacted } \\
\text { - No impact } \\
\text { (ref) }\end{array}$ & 0.88 & $0.52-1.49$ & 0.63 & & & & \\
\hline \multicolumn{8}{|l|}{$\begin{array}{l}\text { Personal income } \\
\text { in the year } 2020\end{array}$} \\
\hline $\begin{array}{c}-\$ 60,000 \text { or } \\
\text { more }\end{array}$ & 0.72 & $0.42-1.24$ & 0.49 & & & & \\
\hline $\begin{array}{l}-\$ 40,000 \text { to } \\
\text { less than } \\
\$ 60,000\end{array}$ & 0.84 & $0.49-1.46$ & & & & & \\
\hline $\begin{array}{l}\text { - Less than } \\
\$ 40,000 \\
\text { (ref) }\end{array}$ & & & & & & & \\
\hline \multicolumn{8}{|l|}{$\begin{array}{l}\text { Effect of COVID- } \\
19 \text { pandemic on } \\
\text { finances }\end{array}$} \\
\hline - Worse & 1.82 & $1.13-2.93$ & 0.047 & & 1.82 & $1.08-3.06$ & 0.024 \\
\hline $\begin{array}{l}\text { - Better } \\
\text { - Same (ref) }\end{array}$ & 1.46 & $0.65-3.36$ & & & 1.33 & $0.54-3.26$ & 0.54 \\
\hline \multicolumn{8}{|l|}{ Cancer type } \\
\hline $\begin{array}{l}\text { - Haemato- } \\
\text { logic } \\
\text { - Non-hae- } \\
\text { matologic } \\
\text { (ref) }\end{array}$ & 0.82 & $0.50-1.33$ & 0.42 & & & & \\
\hline \multicolumn{8}{|l|}{$\begin{array}{l}\text { Time off cancer } \\
\text { treatment }\end{array}$} \\
\hline$-5-10$ years & 1.09 & $0.33-2.68$ & 0.62 & & & & \\
\hline$-2-5$ years & 1.26 & $0.80-1.98$ & & & & & \\
\hline $\begin{array}{l}-1-2 \text { years } \\
\text { (ref) }\end{array}$ & & & & & & & \\
\hline \multicolumn{8}{|l|}{$\begin{array}{l}\text { Pre-pandemic } \\
\text { mental health } \\
\text { condition }\end{array}$} \\
\hline $\begin{array}{l}\text { - Yes } \\
\text { - No (ref) }\end{array}$ & 2.30 & $1.34-3.95$ & 0.02 & & 1.88 & $1.03-3.42$ & 0.038 \\
\hline
\end{tabular}


Table 3 (continued)

\begin{tabular}{|c|c|c|c|c|c|c|}
\hline & \multicolumn{3}{|c|}{ Univariable analysis } & \multirow[b]{2}{*}{ Adjusted odds ratio } & \multicolumn{2}{|l|}{ Multivariable analysis $(n=332)$} \\
\hline & Odds ratio & $95 \% \mathrm{CI}$ & P-Value & & $95 \% \mathrm{CI}$ & P-Value \\
\hline \multicolumn{7}{|l|}{$\begin{array}{l}\text { Pre-existing } \\
\text { chronic physical } \\
\text { health condition }\end{array}$} \\
\hline $\begin{array}{l}\text { - Yes } \\
\text { - No (ref) }\end{array}$ & 1.33 & $0.88-2.00$ & 0.17 & & & \\
\hline \multicolumn{7}{|l|}{$\begin{array}{l}\text { Relationships } \\
\text { status }\end{array}$} \\
\hline $\begin{array}{l}\text { - Single } \\
\text { - In relation- } \\
\text { ship (ref) }\end{array}$ & 0.90 & $0.59-1.36$ & 0.61 & & & \\
\hline \multicolumn{7}{|l|}{$\begin{array}{l}\text { Substance use } \\
\text { during the } \\
\text { pandemic }\end{array}$} \\
\hline - Better & 1.47 & $0.88-2.46$ & 0.33 & & & \\
\hline $\begin{array}{l}\text { - Worse } \\
\text { - Same (ref) }\end{array}$ & 1.26 & $0.71-2.23$ & & & & \\
\hline \multicolumn{7}{|l|}{$\begin{array}{l}\text { Negative impact } \\
\text { of pandemic on } \\
\text { cancer care }\end{array}$} \\
\hline $\begin{array}{l}\text { - Yes } \\
\text { - No (ref) }\end{array}$ & 0.83 & $0.56-1.51$ & 0.75 & & & \\
\hline \multicolumn{7}{|l|}{$\begin{array}{l}\text { Impact of } \\
\text { COVID-19 } \\
\text { pandemic on } \\
\text { physical activ- } \\
\text { ity/exercise }\end{array}$} \\
\hline - More active & 0.87 & $0.46-1.64$ & 0.36 & & & \\
\hline $\begin{array}{l}\text { - Less active } \\
\text { - Same level } \\
\text { of activity } \\
\text { (ref) }\end{array}$ & 1.33 & $0.84-2.10$ & & & & \\
\hline
\end{tabular}

not restricted to only AYAs, making it difficult to compare our results [28]. Another study of sleep in young adult cancer survivors during the COVID-19 pandemic using the ISI found a reduction in insomnia during the pandemic $(50.3 \%$ pre-pandemic vs. $34.3 \%$ during the pandemic). However, this study used an ISI cut-off of 8 (mild insomnia), where we used a cut-off of 15 (moderate/severe insomnia) [55]. A significant increase in insomnia and disordered sleep has been reported in numerous populations during the COVID19 pandemic [56-58]. However, the rate of insomnia in our sample is comparable to the studies using ISI to measure insomnia among the general population during pandemic (20\% vs. $18.6 \%$ and $19.1 \%$ ) $[59,60]$. We demonstrated that survivors who were students, had a haematologic malignancy or were single were more likely to report insomnia. These variables may be a source of increased stress and uncertainty, contributing to insomnia [61]. Students are at high risk of insomnia due to varying routines and periods of intense stress, leading to nearly $60 \%$ of university students reporting poor sleep [45]. Being a student with a previous history of cancer during the COVID-19 pandemic comes with additional stressors such as impacts of the pandemic on cancer care and the inability to meet in person with their support networks [62]. We also demonstrated that survivors with an income of $\geq \$ 60,000$ were at an increased risk of experiencing insomnia. A similar association of higher incomes with high psychological distress was identified in our study. The association of income with insomnia may be confounded by similar factors confounding the impact of income on psychological distress that were not accounted for in this analysis. Insomnia has a bidirectional relationship with depression and can profoundly impact the quality of life, making it a crucial issue to address [63]. Effective insomnia interventions such as cognitive behavioural therapy delivered via in-person or digital format should be available to the survivors with sleep issues [64, 65].

Our study has some important limitations to address. First, our cohort of AYA cancer survivors may not represent 
Table 4 Insomnia among survivors of AYA cancers during the COVID-19 pandemic

\begin{tabular}{|c|c|c|c|c|c|c|c|}
\hline \multirow[b]{2}{*}{ Variable } & \multicolumn{3}{|c|}{ Univariable analysis } & \multirow[b]{2}{*}{$\begin{array}{l}\text { Adjusted } \\
\text { Ratio }\end{array}$} & \multicolumn{3}{|c|}{ Multivariable analysis $(n=279)$} \\
\hline & Odds Ratio & $95 \% \mathrm{CI}$ & P-Value & & Odds & $95 \% \mathrm{CI}$ & P-Value \\
\hline Age (continuous) & 1.01 & $0.97-1.05$ & 0.70 & 0.63 & & $0.30-1.33$ & 0.23 \\
\hline \multicolumn{8}{|l|}{ Gender } \\
\hline - Female & 0.62 & $0.40-0.97$ & 0.034 & & & & \\
\hline \multicolumn{8}{|l|}{ - Male (ref) } \\
\hline \multicolumn{8}{|l|}{ Ethnicity } \\
\hline - Not white & 2.02 & $0.59-6.90$ & 0.26 & & & & \\
\hline \multicolumn{8}{|l|}{ - White (ref) } \\
\hline \multicolumn{8}{|l|}{ Living environment } \\
\hline - Rural/remote & 1.15 & $0.67-1.95$ & 0.62 & & & & \\
\hline \multicolumn{8}{|l|}{ - Urban (ref) } \\
\hline \multicolumn{8}{|l|}{ Employment status } \\
\hline - Unemployed & 2.79 & $1.45-5.38$ & 0.009 & 3.97 & & $1.46-10.83$ & 0.007 \\
\hline - Student & 1.51 & $0.69-3.30$ & & 3.00 & & $1.08-8.29$ & 0.035 \\
\hline \multicolumn{8}{|l|}{ - Employed (ref) } \\
\hline Impact of COVID-19 pandemic on employment & 1.14 & $0.56-2.33$ & 0.71 & & & & \\
\hline \multicolumn{8}{|l|}{ - Impacted } \\
\hline \multicolumn{8}{|l|}{ - No impact (ref) } \\
\hline \multicolumn{8}{|l|}{ Personal income in the year 2020} \\
\hline - $\$ 60,000$ or more & 1.27 & $0.68-2.43$ & 0.060 & & 4.36 & $1.43-13.32$ & 0.010 \\
\hline - $\$ 40,000$ to less than $\$ 60,000$ & 0.61 & $0.31-1.23$ & & & 0.95 & $0.32-2.82$ & 0.93 \\
\hline \multicolumn{8}{|l|}{ - Less than $\$ 40,000$ (ref) } \\
\hline \multicolumn{8}{|l|}{ Effect of COVID-19 pandemic on finances } \\
\hline - Worse & 0.65 & $0.37-1.14$ & 0.30 & & & & \\
\hline - Better & 0.59 & $0.20-1.72$ & & & & & \\
\hline \multicolumn{8}{|l|}{ - Same (ref) } \\
\hline Cancer type & & & & & & & \\
\hline - Haematologic & 2.70 & $1.53-4.66$ & $<0.001$ & & 2.21 & $1.05-4.70$ & 0.039 \\
\hline - Non-haematologic (ref) & & & & & & & \\
\hline Time off cancer treatment & & & & & & & \\
\hline$-5-10$ years & 3.22 & $1.31-3.84$ & 0.006 & & 0.44 & $0.026-7.40$ & 0.57 \\
\hline$-2-5$ years & 2.24 & $0.90-11.5$ & & & 2.01 & $0.94-4.31$ & 0.072 \\
\hline$-1-2$ years (ref) & & & & & & & \\
\hline Pre-pandemic mental health condition & & & & & & & \\
\hline - Yes & 2.10 & $1.18-3.74$ & 0.011 & & 2.19 & $0.85-5.62$ & 0.10 \\
\hline - No (ref) & & & & & & & \\
\hline Pre-existing chronic physical health condition & & & & & & & \\
\hline - Yes & 1.46 & $0.88-2.43$ & 0.15 & & & & \\
\hline - No (ref) & & & & & & & \\
\hline Relationships status & & & & & & & \\
\hline - Single & 1.90 & $1.09-3.30$ & 0.025 & & 2.52 & $1.08-5.91$ & 0.033 \\
\hline - In relationship (ref) & & & & & & & \\
\hline Substance use during the pandemic & & & & & & & \\
\hline - Better & 0.72 & $0.35-1.50$ & 0.009 & & 1.03 & $0.44-2.42$ & 0.94 \\
\hline - Worse & 2.23 & $1.14-.4 .34$ & & & 2.21 & $0.96-5.07$ & 0.061 \\
\hline - Same (ref) & & & & & & & \\
\hline Negative impact of COVID-19 pandemic on cancer care & 2.73 & $1.57-4.75$ & $<0.001$ & & 2.05 & $0.87-4.84$ & 0.10 \\
\hline - Yes & & & & & & & \\
\hline - No (ref) & & & & & & & \\
\hline Impact of COVID-19 pandemic on physical activity/ exe & & & & & & & \\
\hline - More active & 0.94 & $0.40-2.18$ & 0.41 & & & & \\
\hline - Less active & 1.41 & $0.82-2.45$ & & & & & \\
\hline - Same level of activity (ref) & & & & & & & \\
\hline
\end{tabular}


all AYA cancer survivors. For instance, most of our cohort was white (93.0\% vs. $72.6 \%$ of Canadians), and no survivors identified themselves as being from a gender minority group (vs. 0.24\% of Canadians) [66]. Individuals from these minoritized groups have been disproportionately affected by the pandemic; thus, the experiences of AYAs belonging to these groups may differ from those in our cohort [67, 68]. Individuals with limited access to technology may not have been able to access our survey, and these individuals may have had distinct challenges during the pandemic. Interestingly, a systematic review assessing the sample metrics of virtual versus traditional recruitment methods found virtually recruited samples to be more geographically diverse [69]. Comparison of the demographics of our cohort to a prepandemic Canadian survey of AYAs with cancer using both online and paper methods for recruitment revealed that our sample had a greater proportion of rural participants $(33 \%$ vs. $21 \%$ ), suggesting that our online recruitment strategy did not compromise geographic diversity [70]. Our cohort also has very few survivors who completed therapy five or more years ago $(3.1 \%)$. Cancer survivors who are further out from therapy are less likely to seek care in a cancer centre and be involved with support groups and therefore might have been unaware of our study. It is necessary to further study the impact of the COVID-19 pandemic on individuals who are more than five years out from cancer therapy. Our study was done at a single time point during the pandemic when most Canadian provinces were under lockdowns during the second wave of the pandemic. These results may vary as the pandemic goes on for a longer time. The absence of a control group limited our ability to estimate the impact of the pandemic on AYA cancer survivors compared to AYAs without cancer. To combat this limitation, we compared our data to the surveys done in the general population during the pandemic, which, although not ideal, provided more insights into the results. Finally, the presence of distress, loneliness and insomnia might have been overestimated in this cohort of survivors as they were recruited from national AYA support groups.

In summary, we demonstrated that the COVID-19 pandemic had significantly impacted the finances, employment, physical activity, substance use behaviours and cancer care of AYA cancer survivors. Furthermore, we identified that these cancer survivors report higher rates of psychological distress, insomnia and loneliness that require urgent attention. Cancer organizations, non-profit cancer support organizations, primary care providers and the government should focus on developing new programs and promoting existing programs to help mitigate the adverse effects of the COVID19 pandemic on cancer survivors. This is particularly important as the pandemic continues into subsequent waves as the prolonged nature of lockdowns and restrictions may further worsen these challenges.
Supplementary Information The online version contains supplementary material available at https://doi.org/10.1007/s11764-021-01158-9.

Author contributions Conception and Design: All authors.

Collection and Assembly of Data: Adam Yan, Kaitlyn Howden, Camille Glidden, Sapna Oberoi.

Data Analysis and Interpretation: Adam Yan, Kaitlyn Howden, Camille Glidden, Sapna Oberoi.

Manuscript Writing: Adam Yan and Sapna Oberoi.

Final Approval of Manuscript \& accountable for all aspects of the work: All authors.

Funding This work was funded by CancerCare Manitoba Foundation.

Data availability All data are available upon request to the authors.

Code availability Not applicable.

\section{Declarations}

Ethics approval The study was approved by the Research Ethics Board at the University of Manitoba (HS: 24501).

Consent to participate Informed consent to participate was obtained from all participants.

Consent for publication Informed consent to publish was obtained from all participants.

Conflicts of interest No conflicts of interest to declare.

\section{References}

1. Jazieh AR, Chan SL, Curigliano G, et al. Delivering Cancer Care During the COVID-19 Pandemic: Recommendations and Lessons Learned From ASCO Global Webinars. JCO Glob Oncol. 2020;(6). https://doi.org/10.1200/go.20.00423

2. Nekhlyudov L, Duijts S, Hudson SV, et al. Addressing the needs of cancer survivors during the COVID-19 pandemic. J Cancer Surviv. 2020;14(5). https://doi.org/10.1007/s11764-020-00884-w

3. Verbruggen LC, Wang Y, Armenian SH, et al. Guidance regarding COVID-19 for survivors of childhood, adolescent, and young adult cancer: A statement from the International Late Effects of Childhood Cancer Guideline Harmonization Group. Pediatr Blood Cancer. 2020;67(12). https://doi.org/10.1002/pbc.28702

4. Moraliyage H, De Silva D, Ranasinghe W, et al. Cancer in Lockdown: Impact of the COVID-19 Pandemic on Patients with Cancer. Oncologist. 2021;26(2). https://doi.org/10.1002/onco.13604

5. Jazieh AR, Akbulut H, Curigliano G, et al. 1678P_PR The impact of COVID-19 pandemic on cancer care: A global collaborative study. Ann Oncol. 2020;31. https://doi.org/10.1016/j. annonc.2020.08.2325

6. Chan A, Ashbury F, Fitch MI, Koczwara B, Chan RJ. Cancer survivorship care during COVID-19-perspectives and recommendations from the MASCC survivorship study group. Support Care Cancer. 2020;28(8). https://doi.org/10.1007/ s00520-020-05544-4

7. Schulte FSM, Chalifour K, Eaton G, Garland SN. Quality of life among survivors of adolescent and young adult cancer in Canada: A Young Adults With Cancer in Their Prime (YACPRIME) study. Cancer. 2021;127(8). https://doi.org/10.1002/cncr.33372 
8. Wong AWK, Chang T ting, Christopher K, et al. Patterns of unmet needs in adolescent and young adult (AYA) cancer survivors: in their own words. J Cancer Surviv. 2017;11(6). https://doi.org/10. 1007/s11764-017-0613-4

9. Hydeman JA, Uwazurike OC, Adeyemi EI, Beaupin LK. Survivorship needs of adolescent and young adult cancer survivors: a concept mapping analysis. J Cancer Surviv. Published online 2019. https://doi.org/10.1007/s11764-018-0725-5

10. Michel G, François C, Harju E, Dehler S, Roser K. The long-term impact of cancer: Evaluating psychological distress in adolescent and young adult cancer survivors in Switzerland. Psychooncology. 2019;28(3). https://doi.org/10.1002/pon.4981

11. Tonsing KN, Ow R. Quality of Life, Self-Esteem, and Future Expectations of Adolescent and Young Adult Cancer Survivors. Heal Soc Work. 2018;43(1). https://doi.org/10.1093/hsw/hlx047

12. Smith AW, Bellizzi KM, Keegan THM, et al. Health-related quality of life of adolescent and young adult patients with cancer in the United States: The adolescent and young adult health outcomes and patient experience study. J Clin Oncol. 2013;31(17). https:// doi.org/10.1200/JCO.2012.47.3173

13. Halvorsen JF, Sund AM, Zeltzer L, et al. Health-related quality of life and psychological distress in young adult survivors of childhood cancer and their association with treatment, education, and demographic factors. Qual Life Res. 2018;27(2). https://doi.org/ 10.1007/s11136-017-1716-0

14. Graetz D, Agulnik A, Ranadive R, et al. Global effect of the COVID-19 pandemic on paediatric cancer care: a cross-sectional study. Lancet Child Adolesc Heal. 2021;5(5). https://doi.org/10. 1016/S2352-4642(21)00031-6

15. Jammu AS, Chasen MR, Lofters AK, Bhargava R. Systematic rapid living review of the impact of the COVID-19 pandemic on cancer survivors: update to August 27, 2020. Support Care Cancer. 2021;29(6). https://doi.org/10.1007/s00520-020-05908-w

16. Shay LA, Allicock M, Li A. "Every day is just kind of weighing my options." Perspectives of young adult cancer survivors dealing with the uncertainty of the COVID-19 global pandemic. J Cancer Surviv. Published online 2021. https://doi.org/10.1007/ s11764-021-01069-9

17. Košir U, Loades M, Wild J, et al. The impact of COVID-19 on the cancer care of adolescents and young adults and their wellbeing: Results from an online survey conducted in the early stages of the pandemic. Cancer. 2020;126(19). https://doi.org/10.1002/ cncr.33098

18. Hanghøj S, Pappot N, Hjerming M, Taarnhøj GA, Boisen KA, Pappot H. Experiences of Social Isolation during the COVID-19 Lockdown among Adolescents and Young Adult Cancer Patients and Survivors. J Adolesc Young Adult Oncol. Published online 2021. https://doi.org/10.1089/jayao.2020.0202

19. Howden K, Glidden C, Romanescu RG, Hatala A, Scott I, Deleemans J, Chalifour K, Eaton G, Gupta AA, Bolton JM, Mahar AL, Garland SN OSAC-SSE the I of the C-19 P on the CC of A and YACO 2021; 28(4):3201-3213. 10. 3390/curroncol2804027. No Title.

20. Young Adult Cancer Canada. Young Adult Cancer Canada. Accessed August 30, 2021. https://www.youngadultcancer.ca/

21. Millar MM, Dillman DA. Improving response to web and mixed-mode surveys. Public Opin Q. 2011;75(2). https://doi. org/10.1093/poq/nfr003

22. Andrews G, Slade T. Interpreting scores on the Kessler Psychological Distress Scale (K10). Aust N Z J Public Health. Published online 2001. https://doi.org/10.1111/j.1467-842X.2001. tb00310. $\mathrm{x}$

23. Kessler RC, Andrews G, Colpe LJ, et al. Short screening scales to monitor population prevalences and trends in non-specific psychological distress. Psychol Med. Published online 2002. https://doi.org/10.1017/S0033291702006074
24. Steptoe A, Shankar A, Demakakos P, Wardle J. Social isolation, loneliness, and all-cause mortality in older men and women. Proc Natl Acad Sci U S A. Published online 2013. https://doi. org/10.1073/pnas.1219686110

25. Hughes ME, Waite LJ, Hawkley LC, Cacioppo JT. A Short Scale for Measuring Loneliness in Large Surveys. Res Aging. Published online 2004. https://doi.org/10.1177/0164027504 268574

26. Bastien $\mathrm{CH}$, Vallières $\mathrm{A}$, Morin $\mathrm{CM}$. Validation of the insomnia severity index as an outcome measure for insomnia research. Sleep Med Published online. 2001. https://doi.org/10.1016/S13899457(00)00065-4.

27. Morin CM, Belleville G, Bélanger L, Ivers H. The insomnia severity index: Psychometric indicators to detect insomnia cases and evaluate treatment response. Sleep Published online. 2011. https:// doi.org/10.1093/sleep/34.5.601.

28. Savard J, Morin CM. Insomnia in the context of cancer: A review of a neglected problem. J Clin Oncol. Published online 2001. https://doi.org/10.1200/JCO.2001.19.3.895

29. IBM Corp. Released 2020. IBM SPSS Statistics for Windows, Version 28.0. Armonk NIC. No Title.

30. Czeisler MÉ, Lane RI, Petrosky E, et al. Mental Health, Substance Use, and Suicidal Ideation During the COVID-19 Pandemic United States, June 24-30, 2020. MMWR Morb Mortal Wkly Rep. Published online 2020. https://doi.org/10.15585/mmwr. mm6932a1

31. Marjerrison S, Hendershot E, Empringham B, Nathan PC. Smoking, Binge Drinking, and Drug Use Among Childhood Cancer Survivors: A Meta-Analysis. Pediatr Blood Cancer. Published online 2016. https://doi.org/10.1002/pbc.25943

32. Deleemans JM, Zwicker HM, Reynolds KA, Schulte FSM. Associations Among Health Behaviors and Psychosocial Outcomes in Adolescent and Young Adult Cancer Survivors. J Adolesc Young Adult Oncol. Published online 2021. https://doi.org/10.1089/ jayao.2020.0224

33. Canada MHC of. Mental Health and Substance Use During COVID-19.

34. Oberoi S, Robinson PD, Cataudella D, et al. Physical activity reduces fatigue in patients with cancer and hematopoietic stem cell transplant recipients: A systematic review and meta-analysis of randomized trials. Crit Rev Oncol Hematol. 2018;122. https:// doi.org/10.1016/j.critrevonc.2017.12.011

35. Fair D, Park ER, Nipp RD, et al. Material, behavioral, and psychological financial hardship among survivors of childhood cancer in the Childhood Cancer Survivor Study. Cancer. 2021;127(17). https://doi.org/10.1002/cncr.33613

36. De Boer AGEM, Verbeek JHAM, Van Dijk FJH. Adult survivors of childhood cancer and unemployment: A metaanalysis. Cancer. 2006;107(1). https://doi.org/10.1002/cncr.21974

37. Mahon KN, Garland SN, Eaton G, et al. The financial impact of cancer on Canadian young adults. J Cancer Surviv. Published online 2021. doi:https://doi.org/10.1007/s11764-021-00998-9

38. Canada S. Potential Earnings Losses among High School and Postsecondary Graduates Due to the COVID-19 Economic Downturn. Econ Insights: Published online; 2020.

39. Lim J. No Title. Published 2021. Accessed August 31, 2021. https://ipolitics.ca/2021/01/08/canadian-youth-may-suffer-theeconomic-toll-of-covid-for-years-to-come/

40. Geue K, Brähler E, Faller H, et al. Prevalence of mental disorders and psychosocial distress in German adolescent and young adult cancer patients (AYA). Psychooncology. 2018;27(7). https://doi. org/10.1002/pon.4730

41. Lang MJ, Giese-Davis J, Patton SB, Campbell DJT. Does age matter? Comparing post-treatment psychosocial outcomes in young adult and older adult cancer survivors with their cancer-free peers. Psychooncology. 2018;27(5). https://doi.org/10.1002/pon.4490 
42. Statistics Canada. Survey on COVID-19 and Mental Health, September to December 2020. Published 2021. Accessed December 10, 2021. https://www150.statcan.gc.ca/n1/daily-quotidien/ 210318/dq210318a-eng.htm

43. Prout TA, Zilcha-Mano S, Aafjes-van Doorn K, et al. Identifying Predictors of Psychological Distress During COVID-19: A Machine Learning Approach. Front Psychol. 2020;11. https://doi. org/10.3389/fpsyg.2020.586202

44. Holingue C, Badillo-Goicoechea E, Riehm KE, et al. Mental distress during the COVID-19 pandemic among US adults without a pre-existing mental health condition: Findings from American trend panel survey. Prev Med (Baltim). 2020;139. https://doi.org/ 10.1016/j.ypmed.2020.106231

45. Wang Y, Kala MP, Jafar TH. Factors associated with psychological distress during the coronavirus disease 2019 (COVID- 19) pandemic on the predominantly general population: A systematic review and metaanalysis. PLoS One. 2020;15(12 December). https://doi.org/10.1371/journal.pone.0244630

46. Rene Morissette, Martin Turcote, Andre Bernard EO. Workers receiving payments from the Canada Emergency Response Benefit program in 2020No Title. Published 2021. https://www150.statc an.gc.ca/n1/pub/45-28-0001/2021001/article/00021-eng.htm

47. COVID-19 National Survey Dashboard. The Centre for Addiction and Mental Health. Published April 2021. Accessed July 22021. https://www.camh.ca/en/health-info/mental-health-and-covid-19/ covid-19-national-survey. No Title.

48. Miaskowski C, Paul SM, Snowberg K, et al. Loneliness and symptom burden in oncology patients during the COVID-19 pandemic. Cancer. 2021;127(17). https://doi.org/10.1002/cncr.33603

49. Poudel PG, Bauer HE, Srivastava DK, et al. Online Platform to Assess Complex Social Relationships and Patient-Reported Outcomes Among Adolescent and Young Adult Cancer Survivors. JCO Clin Cancer Informatics. 2021;(5). https://doi.org/10.1200/ cci.21.00044

50. Bonsaksen T, Schoultz M, Thygesen H, et al. Loneliness and its associated factors nine months after the covid-19 outbreak: A cross-national study. Int J Environ Res Public Health. Published online 2021. https://doi.org/10.3390/ijerph18062841

51. Tso WWY, Wong RS, Tung KTS, et al. Vulnerability and resilience in children during the COVID-19 pandemic. Eur Child Adolesc Psychiatry. Published online 2020. doi:https://doi.org/ 10.1007/s00787-020-01680-8

52. Carroll N, Sadowski A, Laila A, et al. The impact of covid-19 on health behavior, stress, financial and food security among middle to high income canadian families with young children. Nutrients. 2020;12(8). https://doi.org/10.3390/nu12082352

53. Ernst M, Brähler E, Wild PS, Faber J, Merzenich H, Beutel ME. Loneliness predicts suicidal ideation and anxiety symptoms in long-term childhood cancer survivors. Int J Clin Heal Psychol. Published online 2021. https://doi.org/10.1016/j.ijchp.2020.10. 001

54. Noel CW, Eskander A, Sutradhar R, et al. Incidence of and Factors Associated with Nonfatal Self-injury after a Cancer Diagnosis in Ontario, Canada. JAMA Netw Open. 2021;4(9). https://doi.org/ 10.1001/jamanetworkopen.2021.26822

55. Zhou ES, Michaud AL, Owens J, Recklitis CJ. Sleep in youngadult cancer survivors during the COVID-19 pandemic. J Clin Sleep Med. 2020;16(11). https://doi.org/10.5664/jcsm.8716

56. Alharbi AS, Alshahrani SM, Alsaadi MM, AL-Jahdali HH, Wali SO, BaHammam AS. Sleep quality and insomnia during the covid-19 lockdown among the saudi public. Saudi Med J. Published online 2021. https://doi.org/10.15537/SMJ.2021.42.4. 20200735
57. Huang Y, Zhao N. Generalized anxiety disorder, depressive symptoms and sleep quality during COVID-19 outbreak in China: a web-based cross-sectional survey. Psychiatry Res. Published online 2020. doi:https://doi.org/10.1016/j.psychres.2020.112954

58. Marelli S, Castelnuovo A, Somma A, et al. Impact of COVID-19 lockdown on sleep quality in university students and administration staff. J Neurol. Published online 2021. https://doi.org/10. 1007/s00415-020-10056-6

59. Kokou-Kpolou CK, Megalakaki O, Laimou D, Kousouri M. Insomnia during COVID-19 pandemic and lockdown: Prevalence, severity, and associated risk factors in French population. Psychiatry Res. 2020;290. https://doi.org/10.1016/j.psychres.2020. 113128

60. Bacaro V, Chiabudini M, Buonanno $\mathrm{C}$, et al. Insomnia in the Italian Population During Covid-19 Outbreak: A Snapshot on One Major Risk Factor for Depression and Anxiety. Front Psychiatry. 2020;11. https://doi.org/10.3389/fpsyt.2020.579107

61. Shaffer KM, Applebaum AJ, DuHamel KN, Garland SN, Gehrman P, Mao JJ. Cancer Survivors' Beliefs About the Causes of Their Insomnia: Associations of Causal Attributions With Survivor Characteristics. Behav Sleep Med. Published online 2020. https://doi.org/10.1080/15402002.2018.1546708

62. Muyor-Rodríguez J, Caravaca-Sánchez F, Fernández-Prados JS. Covid-19 fear, resilience, social support, anxiety, and suicide among college students in Spain. Int J Environ Res Public Health. 2021;18(15). https://doi.org/10.3390/ijerph18158156

63. Bajaj S, Blair KS, Schwartz A, Dobbertin M, Blair JRR. Worry and insomnia as risk factors for depression during initial stages of COVID-19 pandemic in India. PLoS One. Published online 2020. https://doi.org/10.1371/journal.pone.0243527

64. Johnson JA, Rash JA, Campbell TS, et al. A systematic review and meta-analysis of randomized controlled trials of cognitive behavior therapy for insomnia (CBT-I) in cancer survivors. Sleep Med Rev. Published online 2016. https://doi.org/10.1016/j.smrv. 2015.07.001

65. Cheng P, Casement MD, Kalmbach DA, Castelan AC, Drake CL. Digital cognitive behavioral therapy for insomnia promotes later health resilience during the coronavirus disease 19 (COVID-19) pandemic. Sleep. Published online 2021. https://doi.org/10.1093/ sleep/zsaa258

66. Statistics Canada. Census Profile, 2016 Census.

67. Boehmer U, Gereige J, Winter M, Ozonoff A. Cancer survivors' access to care and quality of life: Do sexual minorities fare worse than heterosexuals? Cancer. Published online 2019. https://doi. org/10.1002/cncr.32151

68. Ruprecht MM, Wang X, Johnson AK, et al. Evidence of Social and Structural COVID-19 Disparities by Sexual Orientation, Gender Identity, and Race/Ethnicity in an Urban Environment. J Urban Heal. Published online 2021. https://doi.org/10.1007/ s11524-020-00497-9

69. Moseson H, Kumar S, Juusola JL. Comparison of study samples recruited with virtual versus traditional recruitment methods. Contemp Clin Trials Commun. 2020;19. https://doi.org/10.1016/j. conctc. 2020.100590

70. Jones JM, Fitch M, Bongard J, et al. The needs and experiences of post-treatment adolescent and young adult cancer survivors. J Clin Med. 2020;9(5). https://doi.org/10.3390/jcm9051444

Publisher's note Springer Nature remains neutral with regard to jurisdictional claims in published maps and institutional affiliations. 


\section{Authors and Affiliations}

Adam Yan ${ }^{1,2,3} \cdot$ Kaitlyn Howden $^{4} \cdot$ Alyson L. Mahar ${ }^{5,6} \cdot \operatorname{lan}_{\mathrm{Scott}^{7}} \cdot$ Camille Glidden $^{8} \cdot$ Julie Deleemans $^{9}$. Karine Chalifour $^{10}$. Geoff Eaton ${ }^{10} \cdot$ Abha Gupta $^{1,11}$. James M. Bolton ${ }^{5,12} \cdot$ Sheila N. Garland ${ }^{13} \cdot$ Sapna Oberoi ${ }^{4,14,15}$

1 Division of Pediatric Hematology Oncology, The Hospital for Sick Children, University of Toronto, Toronto, Canada

2 Dana-Farber/Boston Children's Blood and Cancer Disorder Center, Boston, MA, USA

3 Harvard Medical School, Boston, MA, USA

4 Department of Pediatrics and Child Health, CancerCare Manitoba, University of Manitoba, 75 McDermot Ave, Winnipeg, MB ON-2015R3E 0V9, Canada

5 Department of Community Health Sciences, Max Rady College of Medicine, University of Manitoba, Winnipeg, Canada

6 Research Institute in Oncology and Hematology, CancerCare Manitoba, Winnipeg, Canada

7 Department of Psychosocial Oncology, CancerCare Manitoba, Winnipeg, Canada

8 Department of Psychiatry, University of Manitoba, Winnipeg, Canada
9 Department of Psychosocial Oncology, University of Calgary Cumming School of Medicine, Calgary, AB, Canada

10 Young Adult Cancer Canada, St. John's, Newfoundland and Labrador, Canada

11 Princess Margaret Cancer Care Research Institute, Toronto, ON, Canada

12 Manitoba Centre for Health Policy, University of Manitoba, Winnipeg, Canada

13 Department of Psychology, Memorial University, St. John's, Newfoundland and Labrador, Canada

14 Department of Pediatric Hematology-Oncology, CancerCare Manitoba, Winnipeg, Canada

15 CancerCare Manitoba Research Institute, CancerCare Manitoba, Winnipeg, MB R3E0V9, Canada 